\title{
International terrorism as a trade impediment?
}

\section{By Peter Egger ${ }^{a}$ and Martin Gassebner ${ }^{b}$}

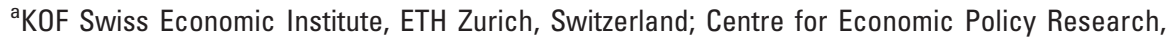
London; CESifo, Germany

${ }^{\mathrm{b}}$ KOF Swiss Economic Institute, ETH Zurich, Switzerland; CESifo, Germany; Institute of Macroeconomics, Leibniz University Hannover, Königsworther Platz 1, 30167 Hannover, Germany; e-mail: gassebner@mak.uni-hannover.de

\begin{abstract}
This article uses monthly data on bilateral trade in conjunction with monthly data on terrorism events and associated fatalities to shed light on the impact of terrorism on trade. Employing a structural model of trade, we provide evidence that, if at all, international terrorism displays effects on bilateral and multilateral trade only in the medium run (more than one and a half years after an attack/incident). The pure short-run impact of international terror on trade appears very small, if not negligible.
\end{abstract}

JEL classifications: D74, F14, F52, H56, 019

\section{Introduction}

The terrorist attacks of 11 September 2001 (9/11) entailed a psychological shock on humankind, which had huge consequences not only directly by way of a human tragedy for the almost 3,000 victims and their relatives but also indirectly, for example, for those who travel internationally by airplane. Thus it would be myopic to measure the impact of those attacks primarily or only in economic terms and, in particular, in short-run responses of economic outcome.

The literature on the consequences of terrorism for international business primarily, but not only, focuses on international terrorism (which involves at least two countries) as an obstacle to the cross-border economic activity-of investment, tourism, or trade. For instance, Abadie and Gardeazabal (2008) find in a cross-section of 110 countries that an increase in terrorist risk at large by 1 standard deviation results in a drop of the net foreign direct investment (FDI) position of about $5 \%$ of GDP for the average economy. Enders and Sandler (1996) report even larger effects for Spain and Greece but no such effects for France, (Western) Germany, and Italy. Enders et al. (2006) focus on US FDI especially after 9/11 and find that except for Turkey the adverse effects on US FDI flows were short-lived. 
Enders et al. (2006) also report a significant but small reduction of US FDI stocks in OECD countries. Eckstein and Tsiddon (2004) find large effects of terrorism on output per capita for Israel.

Enders et al. (1992) estimate the cumulative tourism-related losses due to terrorism at $\$ 16$ billion in continental Europe between 1974 and 1988. However, in 1988 alone the tourism-related revenues were $\$ 74$ billion, so the aforementioned cumulative number appears relatively small in pure economic terms. Drakos and Kutan (2003) confirm the negative effect of terrorism on tourism for Greece, Israel, and Turkey using monthly data for 1991-2000. Additionally, they find support for significant spillover effects. Regarding cross-border flows of people, Dreher et al. (2011) find terrorism to act as a push factor for skilled migrants leading to a brain drain. Moreover, a number of papers find significant and in part sizable effects of international terrorism on the cross-border trade of goods. The next section is devoted to a more detailed discussion of that work.

Most of the research identifying significant disruptive economic effects of terrorism analyzes selected countries with repeated events over longer time spans (most notably Israel, the Basque country, or Ireland). Hence, deriving conclusions from those cases for the average terror event may be misleading. For instance, virtually all attempts made to quantify the pure economic effects of the attacks of $9 / 11$ led to small numbers at least in the longer run (e.g., Chernick, 2005; Bloom, 2009). In that regard, Globerman and Storer (2009) find that there was a reduction of both US exports to and imports from Canada in the aftermath of $9 / 11$. However, the impact of $9 / 11$ on trade is difficult to discern from that of a brief recession in the USA between March and November 2001. The causal impact on international goods transactions with the USA after the attacks was virtually zero, and the effect was mostly seen in a short-term reduction of airborne travels to and from the USA as a consequence of the canceling of flights for several days. Clearly, with the attacks of 9/11 having been by far the most significant events of their kind, we would not expect much smaller individual events-in terms of the number of fatalities or their media echo- to have had bigger purely economic effects.

The aim of this article is to address two potential shortcomings in earlier work of terrorism on international trade: one relating to measurement error through time aggregation bias (an attribution of changes in economic outcome at an earlier point in time to terrorism events at a later point in time) and a second one relating to general equilibrium effects of terrorism. We address the first issue by using monthly data on international terror events to quantify their impact on subsequent international trade within time windows of up to two years. The second issue-existence of general equilibrium effects-is addressed by estimating a structural model of bilateral trade that explicitly accounts for general equilibrium (i.e., direct bilateral trade destruction as well as third-country trade diversion) effects of terrorism on trade. Clearly, in case that terrorism affects GDP-which is a key determinant of bilateral trade-quantifying effects of terrorism on bilateral trade requires respecting general equilibrium effects by way of a simultaneous impact of terrorism on trade and income.

The findings suggest that economic effects through a disruption of international goods trade are very small, in particular, in the short run when using unilateral terror measures (i.e., measuring the effects of terrorism in importing and exporting countries). This finding is not driven by the inclusion or exclusion of countries that received most of the attacks. It turns out that the difference between the small effects identified in this study and the large effects identified in earlier work is indeed due to both time aggregation bias (using annual rather than monthly data) and the neglect of general equilibrium effects in earlier work. 
We review the literature on trade effects of terrorism in detail in the next section. Section 3 outlines the theoretical foundation for our analysis, and Section 4 describes the data. Our results are presented in Section 5, and the final section concludes.

\section{Previous literature}

A number of papers address the topic of how terrorism affects international trade. In general, the literature on effects of terrorism on international trade views terrorism as one example of an iceberg-type (i.e., an ad valorem variable) trade cost factor. Such costs are supposed to exert a negative effect on the volume of bilateral trade by raising insecurity of trade transactions, by disrupting trust in international business relations, by physically destroying transport infrastructure and even goods themselves or the supply of production factors (see Bandyopadhyay and Sandler, 2014), and by rendering cross-border transactions more costly through the increased requirement of security standards.

The first paper in that vein is Nitsch and Schumacher (2004). The authors employ a reduced-form cross-sectional gravity model of bilateral trade-with exports plus imports as the dependent variable-for the years 1968-1979 and incorporate the sum of two trading partners' (log one plus) total terror attacks as a determinant of bilateral trade (alternatively, they use an indicator variable reflecting whether both countries experienced at least one terror attack or measures of other events of political violence). The authors report that a doubling of a pair's terror attacks reduces its total bilateral trade by $4 \%$.

Blomberg and Hess (2006) estimate two variants of a gravity model to assess effects of terrorism on bilateral trade-with exports plus imports divided by two as the dependent variable-using annual panel data for the period of 1968-1999. Terrorism is measured by a binary indicator variable taking the value of 1 if at least one terrorist event was recorded for either country in a trading pair and year. The authors report that bilateral trade falls by $5-6 \%$ if a pair experiences at least one terror incident. Terror is estimated to have a tariff equivalent of $0.65 \%$ to $1.46 \%$ under reasonable assumptions.

Mirza and Verdier (2008) formulate a structural model of bilateral trade with terrorism as one of its (trade-cost-like) determinants. They point to four main issues affecting previous work (see Mirza and Verdier, 2008, p.181): omitted variables bias; persistence of terror and its indirect effect on trade via GDP (a general equilibrium effect as already mentioned); ignorance of a difference between location, target, and perpetrator effects; and a potential bias accruing to reverse causation between terror and trade through the use of terrorism security measures. However, earlier work demonstrated that trade is not a robust determinant of terrorism, so that reverse causation of international terrorism and trade seems of minor importance (see Gassebner and Luechinger, 2011).

De Sousa et al. (2009) use bilateral US panel data at the four-digit Standard International Trade Classification (SITC) level from 1993 to 2002 and analyse the effect of terror against the USA on US imports, focusing on the effect of terror attacks in countries in close proximity to the exporting partner. They find that both terror attacks in the exporting partner and in neighbors of the exporter reduce US imports. ${ }^{1}$ Each attack is estimated to reduce trade by about $1 \%$ when happening in the exporting country and by about $0.5 \%$ when happening in the exporter's neighbouring countries.

1 Since that study focuses on the USA as an importer, effects of terror attacks on US soil are included in the year fixed effect. 
De Sousa et al. (2010) employ a structural gravity model to assess how terror attacks against the USA in the exporter's neighbors may affect US imports over the time span 1993-2006. Relative to De Sousa et al. (2009), they employ a broader concept of (geographical and cultural) neighborhood to assess cross-border spillover effects of terrorism on international trade. They assess how terror attacks in an exporter's neighbour affect US bilateral imports from that exporter, as in De Sousa et al. (2009). They confirm a direct effect of terrorism on bilateral trade, and they find that indirect negative effects of terror from third countries affect US bilateral imports more if the third country is more similar to the exporter.

We may summarize earlier work as follows. First, empirical work used annual panel data or cross-sectional data of trade and (contemporaneous) terrorism to identify the impact of the latter on the former. Second, it mostly employed data on terrorism prior to 9/11. Finally, much of the theoretical and, in particular, the empirical literature on terrorism effects on trade views the effects to materialize via implicit effects on consumer prices (through trade costs and income constraints). To the best of our knowledge, only Bandyopadhyay and Sandler (2014) highlight an additional channel through effects on the supply and redistribution of factors across the sectors of an economy, apart from effects on prices as present also in single-sector economies. In such a framework, Bandyopadhyay and Sandler highlight that the effects of terrorism on trade are ambiguous. The goal of the subsequent analysis is to avoid time aggregation bias and gain a better understanding of the dynamic adjustment of trade to international terrorism by using monthly data on bilateral trade and events data on terrorism, using a large bilateral panel data set which covers the time span 1970-2008. This analysis will respect general equilibrium effects so that direct and indirect (third-country and price as well as income) effects can be discerned.

\section{A structural model of bilateral trade}

We use a linearized structural general equilibrium model of international trade to assess the effects of terrorism on monthly directed trade. Such a model has three virtues. First, it allows assessing not only direct trade destruction effects of terrorism for countries and country-pairs that are exposed to attacks. On the contrary, the model accounts for price (and income) reactions by respecting income constraints (i.e., that total expenditures must equal total income), consistent with general equilibrium. As a consequence, bilateral changes in trade costs-of which terrorist attacks are a part (as in the literature summarized in Section 2)-induce not only bilateral but also multilateral effects. In a nutshell, an increase in bilateral trade costs (e.g., by way of additional terrorist attacks) induces direct negative trade destruction effects, which are cushioned by accompanying, unilateral, negative price and income effects, which affect terror-exposed countries' trade with third countries. Second, it allows avoiding a time aggregation bias of international terror effects on bilateral trade, since terror events later in the year may not have an impact on trade flows earlier in the same year (the later is arguably a major source of endogeneity). In particular, time aggregation bias appears relevant to the extent that some of the trade cost-related aspects of terrorism-especially those related to additional security measures-should be relevant only with delay to an attack. Finally, related to the previous point, the proposed approach permits evidence on the timing of short- to medium-term trade responses to terror attacks.

In broad terms, we follow Baier and Bergstrand (2009) with regard to the model structure. These authors provide a linearization to the estimating equation for bilateral exports or imports as outlined in Anderson and van Wincoop (2003), a structural gravity model of 
bilateral trade that is consistent with multi-country general equilibrium. For convenience, and in line with earlier research, let us denote exporting countries by $i=1, \ldots, I$, importing countries by $j=1, \ldots, J$, time (months) by $t=1, \ldots, T$. In our data with individual OECD country exports, $I=30 \mathrm{~J}=181$, and $T=468$. $^{2}$ Let us use $X_{i j t}$ to denote aggregate nominal sales of country $i$ to country $j$ at time $t, Y_{i t}=\sum_{j=1}^{J} X_{i j t}$ to denote aggregate sales and expenditures of country $i$ at time $t$, and $\theta_{i t}$ to denote country $i$ 's expenditure or sales as a share of world expenditure or sales at time $t .^{3}$ The stochastic version of a general bilateral export equation can thus be written as

$$
\begin{aligned}
\ln \frac{X_{i j t}}{Y_{i t} Y_{j t}} & =\alpha_{t}+\ln \tilde{\tau}_{i j t}^{1-\sigma}+u_{i j t} \\
\ln \tilde{\tau}_{i j t}^{1-\sigma} & =\ln \tau_{i j t}^{1-\sigma}+\ln \Pi_{i t}^{\sigma-1}+\ln P_{j t}^{\sigma-1} \\
& \approx \ln \tau_{i j t}^{1-\sigma}-\left(\sum_{i=1}^{J} \theta_{i t} \ln \tau_{i j t}^{1-\sigma}\right)-\left(\sum_{j=1}^{J} \theta_{j t} \ln \tau_{i j t}^{1-\sigma}\right)+\left(\sum_{j=1}^{J} \theta_{i t} \theta_{j t} \ln \tau_{i j t}^{1-\sigma}\right) .
\end{aligned}
$$

While the representation of the cross-border demand equation based on a gravity model as in Anderson and van Wincoop (2003) in eqs (1) and (2) is exact, the approximation of eq. (2) in eq. (3) is the linearization of the model by Baier and Bergstrand (2009). In line with earlier work, we assume that $\tau_{i j t}^{1-\sigma}$ in eq. (2) is a multiplicative function of $K$ individual elements which are indexed by $k, \tau_{i j t}^{1-\sigma}=\prod_{k=1}^{K} \tau_{k i j t}^{1-\sigma}$, and its $k$ th element depends on the $k$ th observable trade-cost variable $h_{k i j t}, \tau_{k i j t}^{1-\sigma}=h_{k i j t}^{\beta_{k}}$. One element $h_{k i j t}$ captures, for example, a specific international terrorism variable at time $t$ or some period earlier than that as a trade (or transaction) cost. Moreover, $\beta_{k}$ measures the partial (or direct) effect of $h_{k i j t}$ on $\frac{X_{i i t}}{Y_{i t} Y_{j i t}}$. All estimates reported in tables in the empirical analysis of this article will be estimates of $\beta_{k}$. The elements in $\tau_{i j t}$ are measures of iceberg trade costs (Samuelson, 1952). $\alpha_{t}$ is a time-specific constant which captures monthly and seasonal effects, and $u_{i j t}$ is a stochastic disturbance term. Using the jargon of Anderson and van Wincoop (2003), the variables $\Pi_{\mathrm{it}}$ and $P_{j t}^{\sigma-1}$ are so-called exporter and importer multilateral resistance terms, respectively. They measure weighted aggregate trade costs per exporter and time and importer and time, respectively. More formally, $\Pi_{i t}=$ $\left(\sum_{j=1}^{J} \tau_{i j t}^{1-\sigma} P_{j t}^{\sigma-1} \theta_{j t}\right)^{\frac{1}{1-\sigma}}$ and $P_{j t}=\left(\sum_{i=1}^{J} \tau_{i j t}^{1-\sigma} \Pi_{i t}^{\sigma-1} \theta_{i t}\right)^{\frac{1}{1-\sigma}}$. This illustrates that the elasticity of $\frac{X_{i j t}}{Y_{i t} Y_{j t}}$ with respect to $\tau_{i j t}$ is not $1-\sigma$. By the same token, the elasticity of $\frac{X_{i j t}}{Y_{i t} Y_{j t}}$ with respect to the $k$ th observable trade cost variable, $h_{k i j t}$, is not $\beta_{k}$. Moreover, a reduced-form gravity model that disregards general equilibrium would replace $\ln \tilde{\tau}_{i j t}^{1-\sigma}$ by $\ln \tau_{i j t}^{1-\sigma}$ in eq. (1). Notice that the difference between $\ln \tilde{\tau}_{i j t}^{1-\sigma}$ and $\ln \tau_{i j t}^{1-\sigma}$ in the structural model roots in the acknowledgment of the income (or resource) constraint $Y_{i t}=\sum_{j=1}^{J} X_{i j t}$ for all exporting countries and time periods, it. Ignoring the resource constraint implicitly makes $\ln \Pi_{i t}^{\sigma-1}+\ln P_{j t}^{\sigma-1}$ part of the error

2 In case of individual OECD country imports, $j=1, \ldots, 30$ and $i=1, \ldots, 181$.

3 In a one-sector economy with balanced payments, aggregate expenditure and sales correspond to GDP. In the data this does not need to be the case. We come back to that point later. 
term. Then, the parameterized version of trade costs, $\ln \tau_{i j t}^{1-\sigma}$, will not be independent of the corresponding error term and the parameters of interest, $\beta_{k}$, will be biased. ${ }^{4}$

In line with previous research, international terrorism is argued to represent such an iceberg-type cost to the extent that it destroys bilateral trade that would otherwise have taken place. The latter occurs through the destruction of production facilities and goods themselves as two relatively minor obstacles and the destruction of business contacts through increased transportation and travel costs, higher uncertainty, and a deterioration of trust.

We may write bilateral normalized trade flows as

$$
\begin{aligned}
& \ln \frac{X_{i j t}}{Y_{i t} Y_{j t}} \approx \alpha_{t}+\left(\sum_{k=1}^{K} \beta_{k} \ln \tilde{b}_{k i j t}\right)+u_{i j t} \\
& \ln \tilde{h}_{k i j t}=\ln h_{k i j t}-\left(\sum_{i=1}^{J} \theta_{i t} \ln b_{k i j t}\right)-\left(\sum_{j=1}^{J} \theta_{j t} \ln h_{k i j t}\right)+\left(\sum_{j=1}^{J} \theta_{i t} \theta_{j t} \ln b_{k i j t}\right)
\end{aligned}
$$

Hence, all that is needed for estimation are measures of $\ln \frac{X_{i i t}}{Y_{i t} Y_{i t}}, \theta_{i t}$, and $\ln h_{k i i t}$. Whereas $\beta_{k}$ is the parameter on (or partial effect of) $h_{k i j t}$, the total effect (or marginal effect, or elasticity) is approximated by

$$
\frac{\partial \beta_{k} \ln \tilde{h}_{k i j t}}{\partial \ln h_{k i j t}}=\beta_{k}\left(1-\theta_{i t}-\theta_{j t}+\theta_{i t} \theta_{j t}\right) .
$$

Although the marginal effect of trade cost measure $h_{k i j t}$ on bilateral exports or imports accounts for general equilibrium effects, where $-\beta_{k} \theta_{i t}$ dampens the direct effect of $h_{k i j t}$ and represents a unilateral effect of it on all exports of country $i$ at time $t$. Obviously, to the extent that higher trade costs through $h_{k i j t}$ affect export prices of country $i$ at time $t$ in general, the effect of $h_{k i j t}$ on the costs of trade of country $i$ with country $j$ at time $t$ will be relatively smaller. Similarly, $-\beta_{k} \theta_{j t}$ dampens the direct effect of $h_{k i j t}$ and represents a unilateral effect of it on all imports of country $j$ at time $t$. Again, to the extent that higher trade costs through $h_{k i j t}$ affect import prices of country $j$ at time $t$ in general, the effect of $h_{k i j t}$ on the costs of trade of country $j$ with country $i$ at time $t$ will be relatively smaller. $\beta_{k} \theta_{i t} \theta_{j t}$ is a (small) correction factor. The marginal effect in eq. (6) respects GDP accounting and general equilibrium through a multilateral balance of payments, taking into account trade destruction (as the opposite of trade creation) and trade diversion (in the sense of thirdcountry and income effects) through the budget constraint of consumers (see Anderson, 1979; Anderson and van Wincoop, 2003).

Readers who are familiar with panel data econometrics will recognize the similarity between the transformation of trade costs $\ln \tilde{h}_{k i j t}$ in eq. (4) and the so-called within transformation in fixed effects models with two types of fixed effects (see Baltagi, 2008, ch.3). A within estimator with exporter-time and importer-time fixed effects would transform all

4 We admit that $\beta_{k}$ would be inconsistent if observable trade costs such as the terror measures at stake were endogenous. Then, the expected value $E\left(h_{i j t} u_{i j t}\right) \neq 0$. Blomberg and Hess (2006) and Mirza and Verdier (2008) allowed for such an endogeneity. However, we use monthly data, and apart from numbers of attacks, casualties, and deaths as measures of terror, we assume that endogeneity is a negligible problem here. Notice that casualties and death incidents cannot be planned by terrorists, even less so than (successful) attacks. 
trade $\quad$ costs $\quad \ln h_{k i j t} \quad$ into $\quad \ln \breve{h}_{k i j t}=\ln h_{k i j t}-\left(\frac{1}{J} \sum_{i=1}^{J} \ln h_{k i j t}\right)-\left(\frac{1}{J} \sum_{j=1}^{J} \ln h_{k i j t}\right)+$ $\left(\frac{1}{J^{2}} \sum_{j=1}^{J} \ln h_{k i j t}\right)$ (and would do the same with the dependent variable). With symmetric (identical) countries, the model in eq. (5) becomes identical to the latter transformation. Accordingly, eq. (4) represents a quasi two-way within transformation of the right-hand side of the model with exporter-time and importer-time fixed effects so that a correlation of $\ln \tilde{h}_{\text {kijt }}$ with omitted exporter-time-specific or importer-time-specific variables is virtually impossible. Hence, the model in eq. (4) can be estimated by pooling the data across periods and including time-specific but not exporter-time-specific or importer-time-specific fixed effects.

In any case, with international terror events or fatalities in $t$ or prior to $t$ representing some of the elements $\ln h_{k i j t}$, the corresponding parameters $\beta_{k}$ should be interpreted as partial but not as marginal (or total) effects of international terror on bilateral trade. ${ }^{5}$ It is the goal of the subsequent empirical analysis to measure the direct and total effects of trade with respect to terrorism relative to those of other trade costs.

By including contemporaneous as well as lagged terror measures in $\ln \tilde{h}_{k i j t}$ and by measuring $t$ in months, this analysis is capable of avoiding time aggregation bias, accounting for sluggish responses of trade to terror, and respecting general equilibrium (income and thirdcountry) effects altogether. Moreover, using sufficiently many lags of the terror measures, the model may approximate models with dynamic adjustment (see, e.g., Egger, 2001, or Olivero and Yotov, 2012, for gravity models with adjustment dynamics).

\section{Data}

We use data provided by the OECD on monthly, directed, aggregate import, and, alternatively, export flows (in US\$) between 30 individual OECD member countries and 181 partner countries for all 468 months between January 1970 and December 2008. ${ }^{6}$ The total number of trading pairs for which positive trade may be (but is not necessarily) observed per time period is 5,400. Due to the formation of countries after the Cold War, the number of pairs is 5,400 only from 1990 onward but 3,146 before that. ${ }^{7}$ Hence, due to the availability of trade data, 59 countries enter the estimation sample in 1990.

To approximate trade costs akin to the existing literature we rely mainly on data provided by the Centre d'Études Prospectives et d'Informations Internationales (CEPII, see Mayer and Zignago, 2011). We use bilateral variables on colonial heritage and distance. In particular, we employ binary indicator variables for a common border, a common language spoken by at least $9 \%$ of both countries' population, pairs that have been in a colonial relationship, pairs currently in a colonial relationship, 'economies' being identical national entities, and, as a continuous bilateral trade cost measure, the great circle (log) distance

5 We use multilateral international terrorism variables for the exporter and importer by month in the empirical analysis. Using the present notation, such measures would be denoted as $\ln h_{\text {kit }}$ and In $h_{\text {kjt }}$.

6 The data are available at OECD (2012). We refrain from averaging over or summing exports and imports, which is dubbed the 'silver medal mistake' of gravity equations in Baldwin and Taglioni (2006).

7 We provide summary statistics of the variables employed in the empirical analysis in Table A1 and details on the country coverage in Table A2 in the Supplementary Appendix. 
between the most populated cities of two countries. For instance, see Glick and Rose (2002) for the use of those trade cost proxies in gravity models. Moreover, we construct binary variables indicating whether one trading partner or both are landlocked (taken from Easterly and Sewadeh, 2001), World Trade Organization (WTO) members (retrieved from the WTO web page), and whether they are members of the same regional trade agreement (the data have been constructed on the basis of information from the WTO; see Egger and Wamser, 2013), respectively. ${ }^{8}$

Although trade data are available on a monthly basis, GDP is not. To construct the share of country $i$ in world GDP in month $t\left(\theta_{i t}\right)$, monthly GDP data are required. We approximate monthly GDP by using annual GDP together with the monthly share of a country's aggregate annual imports to impute $\theta_{i t}$. Hence, for every country and year, the annual level of GDP is as observed, but its monthly pattern is interpolated. Notice that bilateral and unilateral (total) imports of a country are proportional to its GDP at any point in time, according to the theoretical model employed in this article, whereby not only $Y_{i t}=\sum_{j=1}^{J} X_{i j t}$ (as used in Section 3) but also $Y_{j t}=\sum_{i=1}^{J} X_{i j t}$. Therefore, unilateral imports may be used to 'allocate' annual GDP across the months in a year.'

To measure terrorist activity we use information from the International Terrorism: Attributes of Terrorist Events (ITERATE) database, provided by Mickolus et al. (2009). ITERATE provides data on global terrorist acts, including information on the type of attack, casualties and fatalities, and perpetrators and victims. The data are available for the period 1968-2008 with exact dates. According to Mickolus et al. (2004, p.2):

International/transnational terrorism is the use or threat of use, of anxiety-inducing extranormal violence for political purposes by any individual or group, whether acting for or in opposition to established government authority, when such action is intended to influence the attitudes and behavior of a target group wider than the immediate victims and when, through its location the mechanics of its resolution, its ramifications transcend national boundaries.

ITERATE exclusively focuses on transnational terrorism, that is, the location of the attack, the target of an attack, and/or the perpetrator are not of identical nationalities. Given that our focus is on the effect of terrorism on international trade, this is exactly the type of terrorism we should focus on. ${ }^{10}$

Specifically, we add the total number of terror attacks taking place in a given month and country. We do so for each of the trading partners separately, which allows us to distinguish between effects of terrorism on exporting versus importing. Besides the monthly number of terror attacks, we also obtain the number of persons killed in these attacks (fatalities) and use them as an alternative measure for terror activity. Whereas especially in the recent

8 Please note that we do not include a measure of internal wars given that we model OECD trade we deem that it is not neccessary to do so.

9 As a test of robustness we also used an alternative method to derive the monthly GDP figures. The structural model suggests that there is also a systematic link between fixed month-exporter effects from a model that uses imports by OECD countries from all 192 economies in the data. The monthly time series of those fixed effects is identical to the one of total expenditures on goods, according to the structural model. Using the such-interpolated GDP series relative to the one we use for the following analysis leads to a partial correlation coefficient of 0.8742 .

10 In a sensitivity analysis, we illustrate that taking a broader view of terrorism by accounting for both domestic and transnational terrorism does not alter the findings in qualitative terms. 
past international terrorism seems to be an always present phenomena, attacks are an infrequent event, at least on a worldwide scale. In approximately $90 \%$ of the months in our sample no transnational terror attack has occured. Nontheless it is a widespread phenomenenon as only $16 \%$ of our countries-mostly small island states-did not suffer from a terror attack on their soil.

To gauge the long-run implications of terrorism as opposed to its short- to mediumterm effects, we also construct stock variables of the number of attacks and fatalities by summing incidents from the start of our sample up to the month in question. We do so by using the terror source data to account for all attacks having taken place in a country, irrespective of whether the country was in the estimation sample at that time period.

We provide the summary statistics for all variables employed in the empirical analysis in Table A1 of the Supplementary Appendix.

\section{Empirical results}

\subsection{Parameter estimates}

Table 1 summarizes coefficients which are estimated from a Poisson pseudo-maximum likelihood specification for a gravity model akin to an exponentiated version of eq. (4). The standard errors of that model are robust to clustering at the country-pair level to account for the presence of equi-correlation through repeated observation of the same country-pair across the months in the sample. ${ }^{11}$

Table 1 contains parameters and some further information for eight estimated models, labeled (1)-(8). Models (1)-(4) refer to data on imports by OECD countries from OECD and other countries, while models (5)-(8) refer to data on exports of OECD countries to OECD and other countries. Hence, variables indicating terror events or fatalities for an importer always refer to an OECD country in models (1)-(4), whereas variables indicating terror events or fatalities for an exporter always refer to an OECD country in models (5)-(8). Models with odd numbers include contemporaneous terror events or fatalities only, and models with even numbers include once-lagged stocks along with contemporaneous flows

11 In Table A3 of the Supplementary Appendix, we report coefficients and standard errors for a zero-inflated Poisson model. Notice that bilateral trade flows are zero for more than $34 \%$ of the observations. The latter would lead to an unjustifiable loss of $34 \%$ of the observations with a log-transformed OLS model as in eq. (4). Poisson and zero-inflated Poisson estimators use the observations on zero bilateral trade flows in estimation. It turns out that putting extra weight on the numerous zeros in the data with zero-inflated Poisson estimation does not lead to drastically different results from the Poisson models which give equal weights to the zeros as to other levels of trade flows. Log-transformed OLS models (which are suppressed for the sake of brevity) lead to a sizable bias with the data at hand (see Santos Silva and Tenreyro, 2006, and Egger et al., 2011, for the general problems with OLS in such contexts). Notice that earlier research relied exclusively on such problematic OLS estimates. Due to the qualitative similarity of the Poisson and zero-inflated Poisson models, we focus on the discussion of the former and leave an inspection of the zero-inflated Poisson model estimates in Table A3 to the interested reader. Alternatively to the Poisson quasi-maximum likelihood estimator, one might assume other functional forms of the distribution of disturbances (such as gamma, Gaussian, inverse Gaussian, or negative binomial). However, the consistency of the parameters does not depend on these alternative functional form assumptions and the difference between these estimators tends to be minor even in small samples (see Egger and Staub, 2014). 


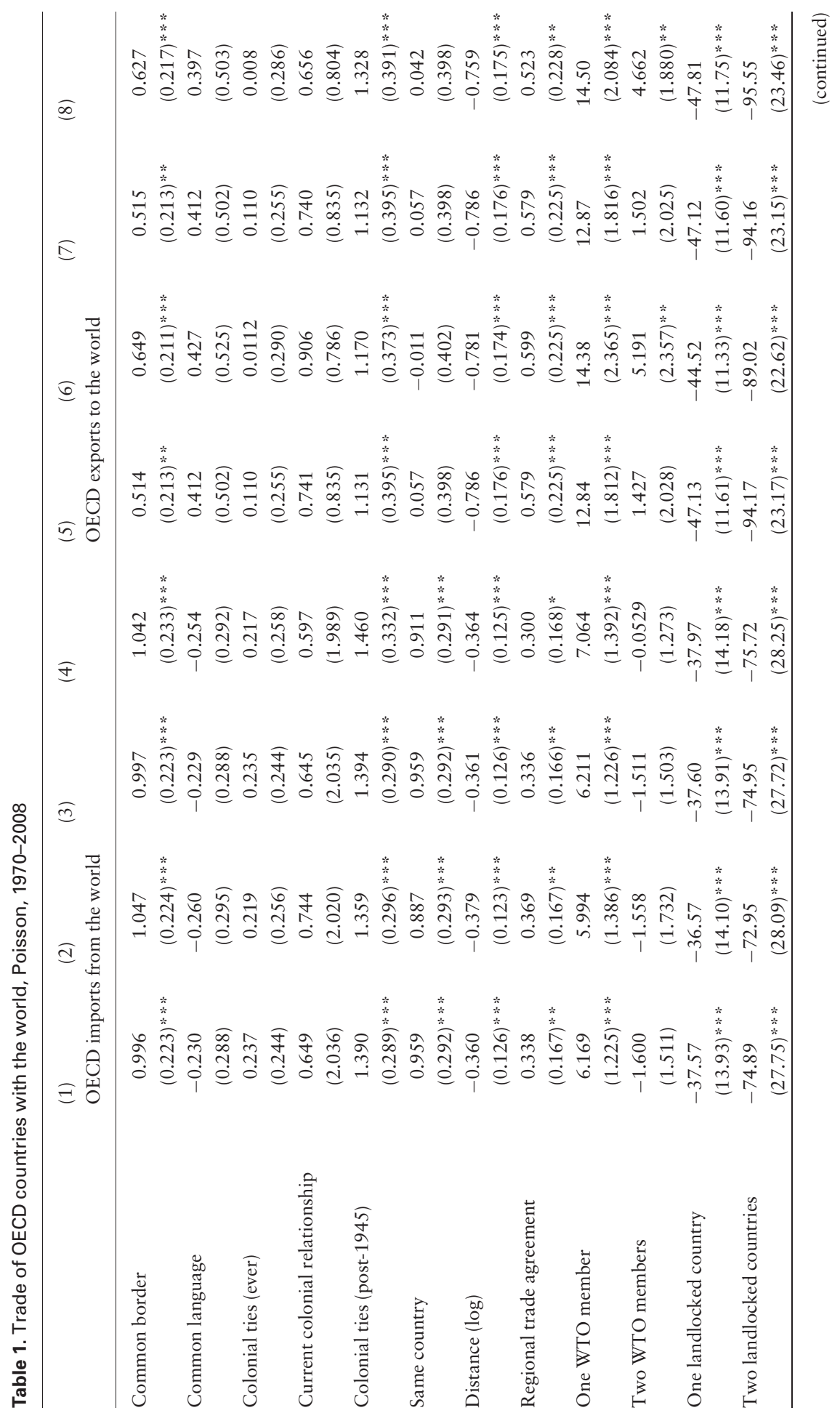




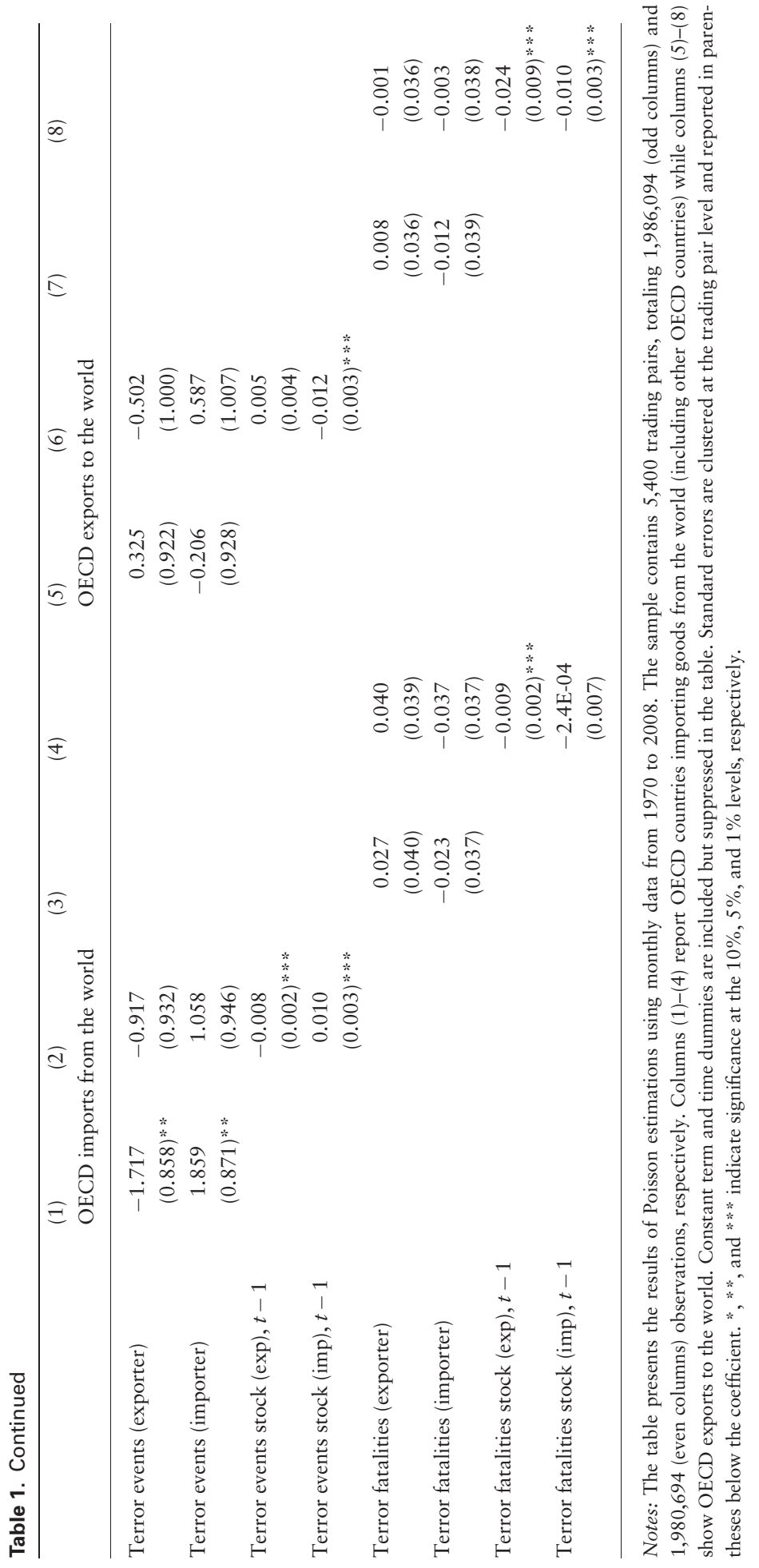


of terror events or fatalities. Hence, models with even numbers allow for insights in longrun effects (assuming an infinite memory within the sample period) of terror on trade while ones with odd numbers focus on short-term (within-the-same-month) effects. The corresponding results can be summarized as follows. ${ }^{12}$

By and large, the results suggest that the general equilibrium-consistent parameters of stocks of lagged terror fatalities in both the exporter and the importer tend to reduce bilateral exports in a given average period, except for the model in column (4). The corresponding short-run effects of contemporaneous new fatalities in columns (3)-(4) and (7)-(8) are never statistically significant. Contemporaneous terror events (rather than fatalities) exert no effects at all-in columns (2), (5), and (6) —or significant effects which are difficult to interpret, being negative for the exporter but positive for the importer. With exception of contemporaneous events effects in column (1), the direct effects as captured by the coefficients tend to be small. The positive coefficient for the importing country is consistent with a rebuilding effort directly after a terror attack. Such behavior is in line with a country's behavior in the aftermath of a natural disaster (see Gassebner et al., 2010).

However, one potential problem with the results in Table 1 is time aggregation bias. Implicitly, we assumed that the process about effects of terror on trade had an infinite memory (in even-numbered columns) or was extremely myopic with a memory of just one month (in odd-numbered columns). Either strategy may lead to a bias of the direct effect of terror on trade as captured by the respective parameters. An intermediate strategy would be to look at dynamic adjustment to the ultimate impact of terror similar to Enders and Sandler (1996).

We consider the latter in Tables 2 and A4 (in the Supplemantary Appendix) which are counterparts to the even-numbered models in Table 1 . These tables discern the contributions of terror events and fatalities during the first 12 months of their occurrence on bilateral trade. Let us again focus on the Poisson results in Table 2 and leave a comparison to the zero-inflated Poisson model approaches in Table A4 in the Supplementary Appendix to the interested reader.

Interestingly, Table 2 suggests rather different conclusions from Table 1 . In fact, there is little evidence of any impact-events or fatalities—of terror on bilateral exports or imports during the first year of their occurrence. This is even true when we look at the cumulative effect of all 12 lags. The sum of the coefficients is only sugnificantly different from zero in specification (1). Moreover, even in this case the sum is positive for the OECD imports further pointing to a rebuilding effort after terror attacks. Hence, the contemporaneous effects of terrorism on bilateral trade in Table 1 are likely driven by time aggregation bias. The latter may partly be associated with the correlation of once-lagged terror stock variables with confounding omitted variables. According to the previous literature, adjustments to terror should materialize at least in part within a year after a fatality or event had occurred. There is no evidence of that. Accordingly, we would conclude that terror does not cause purely economic effects through an impact on bilateral trade. This of course does not mean that terrorism is

12 We focus our discussion on the terror variables due to space constaints. Almost all control variables are similar to previous trade studies. A certain exception are the WTO and landlocked coefficients which seem particularly large. This is driven by the fact that in our sample one trading partner is always an OECD country and thus a WTO member whereas only Luxembourg, Switzerland, the Czech Republic, and the Slovak Republic are landlocked. Both effects are thus not well identified. Excluding these variables does not alter our results. 
Table 2. Trade of OECD countries with the world: terror dynamics, Poisson, 1970-2008

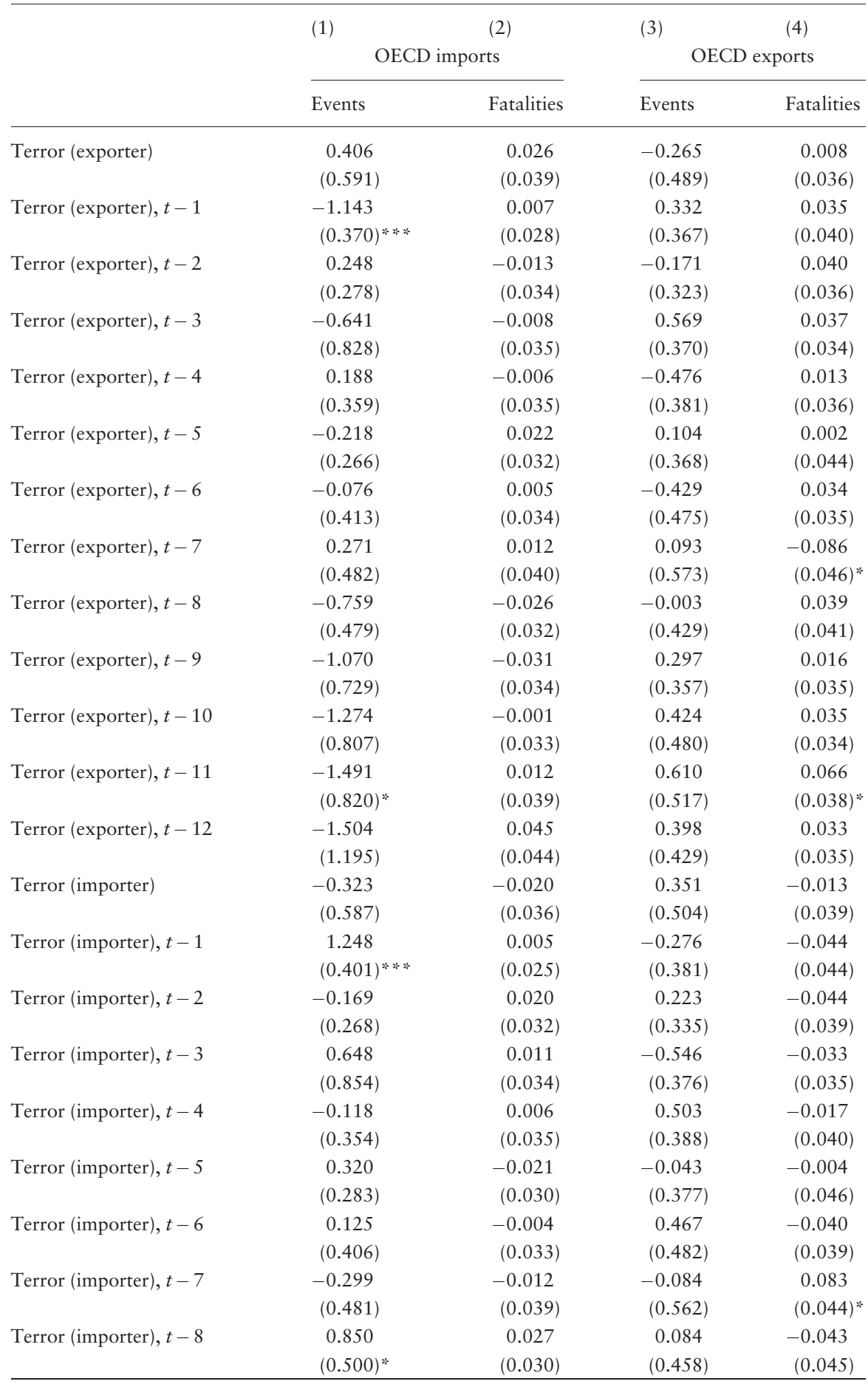


Table 2. Continued

(1) (2)

OECD imports

\begin{tabular}{|c|c|c|c|c|}
\hline & \multicolumn{2}{|c|}{ OECD imports } & \multicolumn{2}{|c|}{ OECD exports } \\
\hline & Events & Fatalities & Events & Fatalities \\
\hline \multirow{2}{*}{ Terror (importer), $t-9$} & 1.119 & 0.027 & -0.296 & -0.020 \\
\hline & $(0.727)$ & $(0.033)$ & $(0.368)$ & $(0.037)$ \\
\hline \multirow[t]{2}{*}{ Terror (importer), $t-10$} & 1.378 & 0.001 & -0.339 & -0.042 \\
\hline & $(0.844)$ & $(0.030)$ & $(0.472)$ & $(0.037)$ \\
\hline \multirow[t]{2}{*}{ Terror (importer), $t-11$} & 1.585 & -0.017 & -0.539 & -0.082 \\
\hline & $(0.809)^{*}$ & $(0.039)$ & $(0.516)$ & $(0.043) *$ \\
\hline \multirow[t]{2}{*}{ Terror (importer), $t-12$} & 1.636 & -0.043 & -0.387 & -0.042 \\
\hline & $(1.238)$ & $(0.044)$ & $(0.434)$ & $(0.037)$ \\
\hline Cumulative effect exporter & 0.029 & 0.917 & 0.651 & 0.529 \\
\hline Cumulative effect importer & 0.015 & 0.958 & 0.791 & 0.466 \\
\hline
\end{tabular}

Notes: See notes to Table 1. The sample contains 5,400 trading pairs, totaling 1,921,294 observations. Cummulative effect reports the $p$-value of a $\chi^{2}$ test $\left(\mathrm{H}_{0}\right.$ : the sum of all importer/exporter terror coefficents is equal to zero). $* * *$, and $* *$ indicate significance at the $10 \%, 5 \%$, and $1 \%$ levels, respectively.

not important. It is well documented that terror has large effects in the political (e.g., Siqueira and Sandler, 2007; Gassebner et al., 2011) or societal (e.g., Silver et al., 2002; Frey et al., 2009) arena, but its mere impact on trade (and probably GDP) is small on average.

The latter conclusion is rather different from earlier work on terror effects on trade, so some discussion is warranted. First, it should be mentioned that the obtained results are not due to the inappropriate aggregation of countries which are strongly versus only mildly exposed to terror. There is no indication whatsoever that a strong exposure to terror leads to a stronger reduction in trade. For instance, we have run the same regressions as for models (1)-(8) in Table 1 but distinguishing the coefficients between the top 10 recipient countries with respect to terror events and fatalities versus all other countries as well as for the 10 countries that exhibit the largest variance over the period $1968-2008 .{ }^{13}$ Those results are not included here for the sake of brevity but are available from the authors on request.

Second, earlier work had not pursued a strategy of using monthly data, but it relied on cross-sectional or annual panel data with a much less precise association of terror dates with trade statistics than is possible with monthly statistics. Hence, there is a chance of time aggregation bias, which we were able to avoid or at least reduce by using monthly data.

Third, earlier work did not control for third-country effects associated with general equilibrium. Anderson and van Wincoop (2003) showed that an ignorance of such effects tends to lead to exaggerated effects of trade costs, and we can think of terror to be an example of trade costs in broad terms. Hence, controlling for problems associated with the

13 Let us use '10' to indicate top-10 recipients, 'var' to indicate countries among the ones with the 10 highest variances, '- $a$ ' attacks, and '- $f$ ' fatalities. Then, these countries are: Afghanistan (10-f), Angola (10-f, var-f), Argentina (10-a, var-a), Canada (var-f), Colombia (10-a, 10-f), France (10-a, vara), Germany (10-a, var-a), Greece (10-a), India (10-f, var-a), Indonesia (var-f), Iraq (10-f, var-a, var$f)$, Israel (10-f), Italy (10-a), Kenia (var-f), Lebanon (10-a, 10-f, var-a, var-f), Malaysia (var-a), Netherlands (var-a), Pakistan (10-f), Russia (10-f, var-f), Spain (var-f), Turkey (10-a), UK (10-a, 10-f, var-a, var-f), USA (10-a, var-a, var-f). 
$\log$ of gravity (Santos Silva and Tenreyro, 2006), with general equilibrium effects (see Anderson and van Wincoop, 2003), and with time aggregation bias, economic effects of terror on trade are negligible, according to our findings relative to those in the literature.

\subsection{Robustness}

Apart from the regressions in Tables 1-2 and A3-A4, we assessed the robustness of our findings along three lines: the lag structure (timing) of effects of international terror incidents and fatalities, respectively; the use of a broader concept of terror incidents and fatalities (domestic plus international terror instead of international terror events only); and the use of gravity models without multilateral resistance terms to see whether the data, the econometric approach, or the multilateral modeling of terror (and other trade cost) effects is responsible for the difference between our (small) effects and the (large) ones in the literature.

With regard to the timing of effects, it turns out that the results are qualitatively robust when considering up to 24 months rather than only 12 months. ${ }^{14}$ Tables A5 and A6 provide counterparts to Tables 2 and A4, being based on Poisson and zero-inflated Poisson regressions, respectively. However, it should be mentioned that a few time lags appear significant when considering longer windows, pointing to some inertia in the materialization of terror effects on trade. However, the accumulated direct trade response to international terror is negative and significant only for the exporting partners of OECD countries in Table A5 (at the 5\% level).

To see whether our results also hold for an alternative more extreme measure of terrorism, we consider only terror attacks in which at least one person was killed. The results are presented in the supplementary appendix in Table A7. Several individual lagged terror coefficients now appear to be statistically significant. The cumulative effects for all lags are also statistically different from zero. However, the total effect for OECD countries is positve, indicating further that OECD countries go into a rebuilding mode after the worst terror attacks.

Considering not only international but total terror (i.e., international plus domestic terrorism) when looking at the effects of trade requires a different data source. ${ }^{15}$ In particular, such information is available from the Global Terrorism Database (GTD), which again permits distinguishing between terror incidents and fatalities. ${ }^{16}$ Although the average number of international terror events in the data as used in Tables 1 and 2 amounts to 0.34 and 0.15 incidents and 0.18 and 0.18 fatalities per month for the average OECD/partner country, these numbers are 1.49 and 1.14 and 1.19 and 2.72, respectively, when considering domestic and international terror combined. Only 13 countries in the world have not experienced at least one terror attack in the sample period accoring to this definition.

14 An alternative modeling approach would be using a transfer function methodology. We calculated the partial correlations for all our terror measures and found them to be low (ranging from 0.401 to -0.003 ). We thus stick with our approach of identifying the individual effects of the lags.

15 In domestic terror events all actors have the nationality of the state where the attacks take place. In the literature domestic terrorism is shown to have different dynamics and determinants as compared to international terrorism (e.g., Savun and Phillips, 2009; Enders et al., 2011).

Available at National Consortium for the Study of Terrorism and Responses to Terrorism (2013). 
Turkmenistan is the largest among these countries. ${ }^{17}$ However, it turns out that considering the broader definition of terror leads to very similar terror elasticities of trade to the ones in Tables 1 and 2. Hence, no matter of whether we apply a more narrow or a broader terror concept, the pure trade-induced economic effects of terror are small. ${ }^{18}$

\subsection{Total effects of terrorism on trade}

Remember that the coefficients reported in the regression tables only reflect direct effects of trade costs. The total effect of trade cost $h_{k i j t}$ on bilateral trade can be approximated by eq. (6). This is the case as long as the impact of terror is small so that total expenditure per country and time remains unchanged. It turns out that the average $\theta_{i t}$ for an OECD country is roughly 0.03 , whereas for all countries it is 0.006 . Thus for the average countrypair one has to multiply the coefficients in the table by about $(1-0.03-0.006+$ $0.03 \cdot 0.006) \approx 0.96$. For specific countries and country-pairs, this can be very different, of course. For the USA (our 'largest country') and its 'average' partner, the corresponding weighting factor is 0.7 . However, this shows that the coefficients approximate total elasticities quite well except for the largest economies in the sample. Notice that other authors had controlled for general equilibrium effects by including fixed country effects with crosssection data and fixed country-time effects with panel data (see, e.g., Blomberg and Hess, 2006). However, such a procedure only permits consistent estimation of the direct effect of terrorism on trade (captured by $\beta_{k}$ ) but not calculation of general equilibrium comparative static effects.

\subsection{Discussion}

It appears worthwhile to investigate which one of three differences (considering general equilibrium effects, differentiating between effects on exporters and importers, or using monthly data) is key for the starkly different results in this paper from the ones identified in previous research. To shed light on this matter, we replicate the set-up from Blomberg and Hess (2006) with our data.

In Table 3, we employ an OLS estimator and refrain from transforming our variables to account for general equilibrium effects of terror and other trade costs and use a binary variable which is unity if a terror attack happens in at least one of the two training partners and zero otherwise. Although we think that our approach described above is superior, using the binary variable replicates the method chosen by Blomberg and Hess (2006). Among other things a binary variable does not allow us to control for different terror intensities. The coefficients from the associated regressions are directly comparable to the ones in Blomberg and Hess (2006) — though based on a different source, sample and (most importantly) frequency of the data. Notable differences between the parameter estimates in this study and the one of Blomberg and Hess are found only for the WTO variables and the common border measure. The former is due to the diffent sample (note that in our study at least one country is always an OECD country and hence WTO member). In spite of the aforementioned differences between the two studies, the discrepancy in the parameter estimates appear to be small. It turns out that this alternative model leads to a very similar direct trade elasticity of international

17 The other countries without an attack in our sample period are: Cape Verde, Micronesia, Greenland, Kiribati, St. Lucia, Marshall Islands, Oman, Palau, Tonga, Tuvalu, and St. Vincent and the Grenadines. 
Table 3. Replication of Blomberg and Hess (2006, Table 1, column 3)

\begin{tabular}{|c|c|c|}
\hline & $\begin{array}{l}(1) \\
\log (\text { imports })\end{array}$ & $\begin{array}{l}(2) \\
\log (\text { exports })\end{array}$ \\
\hline GDP $(\log )$ (OECD country) & $\begin{array}{c}0.619 \\
(12.20) * * *\end{array}$ & $\begin{array}{c}0.561 \\
(15.60) * * *\end{array}$ \\
\hline GDP $(\log )$ (partner country) & $\begin{array}{c}0.726 \\
(17.54) * * *\end{array}$ & $\begin{array}{c}0.761 \\
(27.55) * * *\end{array}$ \\
\hline Population (log) (OECD country) & $\begin{array}{l}1.841 \\
(6.44) * * *\end{array}$ & $\begin{array}{l}1.075 \\
(4.84) * * *\end{array}$ \\
\hline Population (log) (parnter country) & $\begin{array}{l}-1.443 \\
(14.05)^{* * *}\end{array}$ & $\begin{array}{l}-0.300 \\
(3.94) * * *\end{array}$ \\
\hline Common border & $\begin{array}{r}-0.047 \\
(0.31)\end{array}$ & $\begin{array}{c}-0.188 \\
(1.19)\end{array}$ \\
\hline Common language & $\begin{array}{l}0.413 \\
(5.65) * * *\end{array}$ & $\begin{array}{l}0.481 \\
(8.11)^{* * *}\end{array}$ \\
\hline Colonial ties (ever) & $\begin{array}{l}0.574 \\
(4.44) * * *\end{array}$ & $\begin{array}{l}0.604 \\
(5.38) * * *\end{array}$ \\
\hline Current colonial relationship & $\begin{array}{r}0.680 \\
(0.64)\end{array}$ & $\begin{array}{c}0.658 \\
(0.62)\end{array}$ \\
\hline Colonial ties (post 1945) & $\begin{array}{l}0.976 \\
(5.92) * * *\end{array}$ & $\begin{array}{l}1.079 \\
(6.93)^{* * * *}\end{array}$ \\
\hline Same country & $\begin{array}{c}0.214 \\
(0.84)\end{array}$ & $\begin{array}{c}0.228 \\
(0.77)\end{array}$ \\
\hline Distance $(\log )$ & $\begin{array}{l}-1.094 \\
(25.95) * * *\end{array}$ & $\begin{array}{l}-1.349 \\
(36.10) * * *\end{array}$ \\
\hline Regional trade agreement & $\begin{array}{l}0.337 \\
(6.28) * * *\end{array}$ & $\begin{array}{l}0.322 \\
(6.29) * * *\end{array}$ \\
\hline One WTO member & $\begin{array}{r}-0.008 \\
(0.01)\end{array}$ & $\begin{array}{c}-0.526 \\
(1.78) *\end{array}$ \\
\hline Two WTO members & $\begin{array}{c}0.051 \\
(0.09)\end{array}$ & $\begin{array}{c}-0.473 \\
(1.60)\end{array}$ \\
\hline One landlocked country & $\begin{array}{l}-0.234 \\
(4.36) * * *\end{array}$ & $\begin{array}{l}-0.171 \\
(4.12) * * *\end{array}$ \\
\hline Terror event (dummy) & $\begin{array}{l}-0.052 \\
(5.62) * * *\end{array}$ & $\begin{array}{l}-0.021 \\
(3.42) * * *\end{array}$ \\
\hline Constant & $\begin{array}{l}-21.858 \\
(3.82) * * *\end{array}$ & $\begin{array}{r}-21.401 \\
(4.90) * * *\end{array}$ \\
\hline Observations & $1,303,371$ & $1,421,411$ \\
\hline$R$-squared & 0.74 & 0.81 \\
\hline
\end{tabular}

Notes: The table reports OLS estimation outcomes replicating the results of Blomberg and Hess (2006). Column (1) uses (log of) OECD imports and column (2) uses (log of) OECD exports as dependent variables. The standard error is clustered at the trading pair level and t-values are reported below the coefficient. The terror event dummy variable takes the value of 1 if in at least one country of the pair a terror attack takes place (as in Blomberg and Hess 2006). * $* *$, and $* *$ indicate significance at the $10 \%, 5 \%$, and $1 \%$ levels, respectively. 
terror to the one in Blomberg and Hess (2006). In fact, for OECD imports we basically find an identical coefficient as in Blomberg and Hess (2006, p.605): -0.052 as compared to -0.051 (see column (3) of their Table 1). For OECD exports the coefficient of interest is half as large as the one in Blomberg and Hess but the 95\% confidence intervals overlap: -0.021 (standard error 0.006) as compared to -0.051 (standard error 0.014). ${ }^{19}$

What are reasons for why the effect of terrorism on trade is actually small? One is that terrorism comes at a cost and most countries undertake measures to prevent it (e.g., by way of security controls at ports of entry). For instance, Customs-Trade Partnership Against Terrorism (C-TPAT), a government-private sector partnership which was founded in November 2001 as a result of 9/11, is one of such measures taken by the USA. To quote the institution itself, 'C-TPAT seeks to safeguard the world's vibrant trade industry from terrorists, maintaining the economic health of the US and its neighbors. The partnership develops and adopts measures that add security but do not have a chilling effect on trade, a difficult balancing act' (US Customs and Border Protection, 2014). If companies join the CTPAT, they have to agree to cooperate with the US Customs and Border Protection to get checked less frequently, which speeds up entry into the USA (thus lowering implied trade costs).

The effect of such programs is very difficult to quantify, though. One interesting finding is presented by Globerman and Storer (2009). They show that 9/11 has had some negative effect on US-Canadian trade, but not in ports that used the Fast and Secure Trade (FAST) program more intensively. This program is similar to the C-TPAT but restricted to US-Canadian border trade.

From a general perspective, the identified effects on trade might be small because we cannot account for government expenses (for military, security, etc.) to prevent terrorism due to the lack of available data. Notice that such expenses would modify the approximation in eqs (1)-(6), since instead of GDP shares some of the terms would carry modified expenditure shares (net of government expenses for terrorism prevention). However, for the average economy this would still not involve major changes to the results. For individual countries, the expenses would have to be large (as they arguably are for countries such as Israel) relative to consumption expenditures to obtain largely different results from those that have been identified above.

Moreover, one might think that-apart from an economic effect of terrorism through an increase in uncertainty or in transaction costs-there is a disruptive effect on transport and even production infrastructure. However, this effect should be small on average (with the obvious exception of countries such as Israel, Iraq, or Colombia).

Finally, one should take into account that the very nature of terrorism has changed with potential consequences for its economic effects. While targets of terrorism used to be government officials and business, more recent attacks increasingly target random private parties (see Brandt and Sandler, 2010). Although this might amplify the shock effect on the population and indirectly increase pressure on government, the associated direct economic consequences for trade might be smaller.

19 Recall that Blomberg and Hess (2006) used annual panel data for 177 countries and the period 1968-1999. However, this does not appear to matter for the results. What is important is the consideration of third-country effects (see Anderson and van Wincoop, 2003, for similar insights in the context of US border effects). 


\section{Conclusions}

Revisiting the question of whether terrorism bears direct economic costs, this article analyses to which extent terror deters international trade. In contrast to most of the earlier works, we do not find a strong negative effect of terrorism on trade. We arrive at that conclusion by using monthly (rather than annual or cross-section) data from 1970 to 2008 using a structural (rather than an ad hoc) gravity model approach accounting for general equilibrium effects. Although the data set employed is unique, it is not the reason for the difference of our findings relative to earlier work. The data at hand permit replicating previous findings once ignoring the exact (monthly) timing of terror incidents and possible trade responses. This suggests that part of the 'common wisdom' about economic effects of terrorism is built on results that suffer from time aggregation bias by way of misattribution of changes of trade in the past to terror events in the future. With our setup we cannot give a final evaluation of the specific bilateral effects of terrorism within a trading pair, that is, how does a terror attack of nationals of country $\mathrm{X}$ against citizens of $\mathrm{Y}$ affect the trade flows between $\mathrm{X}$ and $\mathrm{Y}$ specifically. We do cover the more general unilateral effect of terrorism, however.

To us, moderate effects of terrorism on trade do not seem implausible. Although terrorism targeted mainly government officials and business directly in the past, it is relatively more focused on private parties nowadays (Brandt and Sandler, 2010). Moreover, the average terror event is relatively small and, for countries and country-pairs, infrequent. Certainly, that does not mean that terror does not matter. It says, though, that trade might be the wrong domain to look for big effects. Whereas earlier work on terrorism and trade could not address effects of terror beyond trade, the use of a structural model in this article permits a broader analysis. In fact, the results suggest that on average, the effects of terror not only on trade but also on income (and, by that token, on growth) are negligible. This is consistent with recent work reporting no significant effect of terrorism on economic growth (see Gaibulloev et al., 2014). The special role of fatal terror attacks warrants a further exploration in future research.

\section{Supplementary material}

Supplementary material is available online at the OUP website.

\section{Acknowledgements}

We thank Anindya Banerjee, Tilman Brück, Rainer Lanz, Todd Sandler, two anonymous referees, and participants of following conferences: the World Public Choice Meeting Miami, the International Political Economy Society at the University of Virginia, the Travemünde Symposium on the Economic Analysis of Law, the Terrorism and Policy Conference Dallas, the German Economic Association Hamburg, as well as seminar participants at the Universities of Freiburg, Lucerne, and Salzburg for helpful input on earlier versions of this article.

\section{Funding}

Czech Science Foundation (P402/12/0982). 


\section{References}

Abadie, A. and Gardeazabal, J. (2008) Terrorism and the world economy, European Economic Review, 52, 1-27.

Anderson, J.E. (1979) A theoretical foundation for the gravity equation, American Economic Review, 69, 106-16.

Anderson, J.E. and van Wincoop, E. (2003) Gravity with gravitas: a solution to the border puzzle, American Economic Review, 93, 170-92.

Baier, S.L. and Bergstrand J.H. (2009) Bonus vetus OLS: a simple method for approximating international trade-cost effects using the gravity equation, Journal of International Economics, $77,77-85$.

Baldwin, R.E. and Taglioni, D. (2006) Gravity for dummies and dummies for gravity equations, NBER Working Paper 12516, National Bureau of Economic Research.

Baltagi, B.H. (2008) Econometric Analysis of Panel Data, 4th edn., Wiley, Chichester.

Bandyopadhyay, S. and Sandler, T. (2014) The effects of terrorism on trade: a factor supply approach, Federal Reserve Bank of St. Louis Review, 96, 229-41.

Blomberg, S.B. and Hess, G.D. (2006) How much does violence tax trade?, Review of Economics and Statistics, 88, 599-612.

Bloom, N. (2009) The impact of uncertainty shocks, Econometrica, 77, 623-85.

Brandt, P.T. and Sandler, T. (2010) What do transnational terrorists target? Has it changed? Are we safer?, Journal of Conflict Resolution, 54, 214-36.

Chernick, H. (2005) Resilient City: The Economic Impact of 9/11, Russell Sage Foundation, New York.

De Sousa, J., Mirza, D., and Verdier, T. (2009) Trade and the spillovers of transnational terrorism, Swiss Journal of Economics and Statistics, 145, 453-61.

De Sousa, J., Mirza, D., and Verdier, T. (2010) Terrorism networks and trade: does the neighbor hurt?, CEPR Discussion Paper No. 7946, Centre for Economic Policy Research.

Drakos, K. and Kutan, A.M. (2003) Regional effects of terrorism on tourism in three Mediterranean countries, Journal of Conflict Resolution, 47, 621-41.

Dreher, A., Krieger, T., and Meierrieks, D. (2011) Hit and (they will) run: the impact of terrorism on migration, Economics Letters, 113, 42-46.

Easterly, W. and Sewadeh, M. (2001) Global Development Network Growth Database, World Bank, Washington, DC.

Eckstein, Z. and Tsiddon, D. (2004) Macroeconomic consequences of terror: theory and the case of Israel, Journal of Monetary Economics, 51, 971-1002.

Egger, P.H. (2001) European exports and outward foreign direct investment: a dynamic panel data approach, Review of World Economics/Weltwirtschaftliches Archiv, 137, 427-49.

Egger, P.H., Larch, M., Staub, K., and Winkelmann, R. (2011) The trade effects of endogenous preferential trade agreements, American Economic Journal: Economic Policy, 3, 113-43.

Egger, P.H. and Staub, K. (2014) GLM estimation of trade gravity models with fixed effects, Mimeo, University of Melbourne.

Egger, P.H. and Wamser, G. (2013) Multiple faces of preferential market access: their causes and consequences, Economic Policy, 28, 143-87.

Enders, W., Sachida, A., and Sandler, T. (2006) The impact of transnational terrorism on U.S. foreign direct investment, Political Research Quarterly, 59, 517-31.

Enders, W. and Sandler, T. (1996) Terrorism and foreign direct investment in Spain and Greece, Kyklos, 49, 331-52.

Enders, W., Sandler, T., and Gaibulloev, K. (2011) Domestic versus transnational terrorism: data, decomposition, and dynamics, Journal of Peace Research, 48, 319-37.

Enders, W., Sandler, T., and Parise, G.F. (1992) An econometric analysis of the impact of terrorism on tourism, Kyklos, 45, 531-54. 
Frey, B.S., Luechinger, S., and Stutzer, A. (2009) The life satisfaction approach to valuing public goods: the case of terrorism, Public Choice, 138, 317-45.

Gaibulloev, K., Sandler, T., and Sul, D. (2014) Dynamic panel analysis under cross-sectional dependence, Political Analysis, 22, 258-73.

Gassebner, M., Jong-A-Pin, R., and Mierau, J.O. (2011) Terrorism and cabinet duration, International Economic Review, 52, 1253-70.

Gassebner, M., Keck, A., and Teh, R. (2010) Shaken, not stirred: the impact of disasters on international trade, Review of International Economics, 18, 351-68.

Gassebner, M. and Luechinger, S. (2011) Lock, stock, and barrel: A comprehensive assessment of the determinants of terror, Public Choice, 149, 235-61.

Glick, R. and Rose, A.K. (2002) Does a currency union affect trade? The time-series evidence, European Economic Review, 46, 1125-51.

Globerman, S. and Storer, P. (2009) The effects of 9/11 on Canadian-U.S. trade: an update through 2008, Brookings Instuitution.

Mayer, T. and Zignago, S. (2011) Notes on CEPIIs distances measures: The GeoDist Database, CEPII Working Paper 2011-25, Centre d'Études Prospectives et d'Informations Internationales, Paris.

Mickolus, E.F., Sandler, T. Murdock, J.M., and Flemming, P.A. (2004) International Terrorism: Attributes of Terrorist Events (ITERATE): 1968-2004, Data Codebook, Vinyard Software, Dunn Loring, VA.

Mickolus, E.F., Sandler, T. Murdock, J.M., and Flemming, P.A. (2009) International Terrorism: Attributes of Terrorist Events (ITERATE): 1968-2008, Vinyard Software, Dunn Loring, VA.

Mirza, D. and Verdier, T. (2008) International trade, security and transnational terrorism: theory and a survey of the empirics, Journal of Comparative Economics, 36, 179-94.

National Consortium for the Study of Terrorism and Responses to Terrorism (START). (2013) Global Terrorism Database, available at http://www.start.umd.edu/gtd.

Nitsch, V. and Schumacher, D. (2004) Terrorism and international trade: an empirical investigation, European Journal of Political Economy, 20, 423-33.

OECD. (2012) International trade by partner country; monthly, available at http://www.oecd.org/

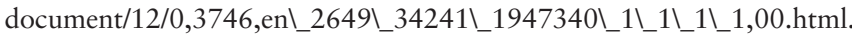

Olivero, M.P. and Yotov, Y.V. (2012) Dynamic gravity: endogenous country size and asset accumulation, Canadian Journal of Economics, 45, 64-92.

Samuelson, P. (1952) The transfer problem and the transport costs: the terms of trade when impediments are absent, Economic Journal, 62, 278-304.

Santos Silva, J.M.C. and Tenreyro, S. (2006) The log of gravity, Review of Economics and Statistics, 88, 641-58.

Savun, B. and Phillips, B.J. (2009) Democracy, foreign policy, and terrorism, Journal of Conflict Resolution, 53, 878-904.

Silver, R.C., Holman, E.A., McIntosh, D.N., Poulin, M., and Gil-Rivas, V. (2002) Nationwide longitudinal study of psychological responses to September 11, Journal of the American Medical Association, 288, 1235-44.

Siqueira, K. and Sandler, T. (2007) Terrorist backlash, terrorism mitigation, and policy delegation, Journal of Public Economics, 91, 1800-1815.

US Customs and Border Protection. (2014) C-TPAT: Customs-Trade Partnership Against Terrorism, available at http://www.cbp.gov/border-security/ports-entry/cargo-security/c-tpatcustoms-trade-partnership-against-terrorism. 